\title{
TECNOLOGIAS DIGITAIS NAS PRÁTICAS DOS PROFESSORES QUE ENSINAM MATEMÁTICA: RELAÇÕES COM A FORMAÇÃO CONTINUADA
}

\author{
MARIA IVETE BASNIAK \\ Universidade Estadual do Paraná \\ basniak2000@yahoo.com.br
}

\section{SANI DE CARVALHo RUTZ dA SilVA}

Universidade Tecnológica Federal do Paraná

sani@utfpr.edu.br

\section{RESUMO}

Objetivamos no presente trabalho discutir como as tecnologias digitais se fazem presentes nas práticas dos professores que ensinam matemática e como se relacionam às formações que receberam sobre tecnologias na educação e para o ensino de Matemática. Tomamos como pressupostos teóricos os trabalhos de Valente $(1993,1997,1999)$ de que o uso inteligente do computador requer práticas assumidas pelo professor que ultrapassem o seu uso como máquina de ensinar e o assumam como ferramenta de ensino. Dessa forma, nossa pesquisa caracteriza-se como uma pesquisa de cunho qualitativo, em que tomamos como elementos de análise as respostas de quatorze professores da Educação Básica a um questionário de respostas abertas. Os resultados apontam que precisamos repensar a formação de professores em relação às tecnologias na educação privilegiando o caráter pedagógico ao instrumental, já que identificamos que os professores reproduzem as formações que recebem ao utilizarem tecnologias em sala de aula, privilegiando a verificação de resultados, simulações e resolução de exercícios. Então, concluímos que as respostas dos professores ao questionário revelam que as tecnologias quando utilizadas em sala de aula pelos professores apresentam as características do ensino tradicional computadorizado, e, não são, portanto, utilizadas como ferramentas educacionais.

Palavras-chave: Tecnologia. Formação de Professores. Práticas de Professores.

\section{DIGITAL TECHNOLOGIES IN THE PRACTICES OF TEACHERS WHO TEACH MATHEMATICS: RELATIONS WITH CONTINUED TRAINING}

\section{ABSTRACT}

We aim in this work to discuss how digital technologies are present in the practices of teachers who teach mathematics and how they relate to the training they have received on technologies in education and to teaching mathematics. We take as theoretical assumptions the works of Valente $(1993,1997,1999)$ that the intelligent use of the computer requires practices assumed by the teacher that surpass its use as a teaching machine and assume it, as a teaching tool. Thus, our research is characterized as a qualitative research, in which we take as elements of analysis the 
responses of fourteen teachers of Basic Education to a questionnaire of open answers. The results point out that we need to rethink teacher education in relation to technologies in education, favoring the pedagogical and instrumental character, since we identify that teachers reproduce the training they receive when using technologies in the classroom, favoring the verification of results, simulations and resolution of exercises. We conclude that teachers' responses to the questionnaire reveal that, technologies used in the classroom by teachers present the characteristics of traditional computerized teaching and are therefore not used as educational tools.

\section{KEYWORDS:}

Technology. Teacher training. Teacher Practices.

\section{INTRODUÇÃO}

A presente pesquisa objetiva debater como as tecnologias digitais que estão inseridas nas escolas por meio de recursos ${ }^{1}$, dos quais destacamos computadores e tablets com acesso a internet e com diferentes softwares e aplicativos, se fazem presentes nas práticas dos professores que ensinam matemática e como as formações desses professores têm influenciado nesse sentido, pois, apesar de recursos tecnológicos, laboratórios de informática principalmente, virem sendo instalados nas escolas há alguns anos, e formações de professores serem realizadas para o uso desses recursos, que pode ser verificado pelo Programa Nacional de Tecnologias na Educação (Prolnfo) desde 1997, não temos verificado mudanças na metodologia do trabalho do professor em sala de aula.

Assim, primeiramente, discutimos como o computador pode contribuir para alternativas de ensino superarem a transmissão do conhecimento nas aulas de matemática, favorecendo a participação do aluno de forma ativa no processo de aprendizagem. Problematizamos também a formação dos professores em relação às tecnologias educacionais, em que normalmente é privilegiada a parte instrumental a pedagógica.

\footnotetext{
${ }^{1}$ Segundo levantamento de materiais disponíveis nas escolas pelo GETIEM no portal educacional Dia a dia Educação. Disponível em: http://www.consultaescolas.pr.gov.br/consultaescolas/f/fcls/estado/consultaslnfraestrutura.xhtml 
Após, apresentamos a metodologia do trabalho que foi estruturada por meio de pesquisa qualitativa, pautada empiricamente em questionários, respondidos por professores da Educação Básica, cujas análises e conclusões são discutidas na sequência.

\subsection{O USO DO COMPUTADOR NO ENSINO E SUA RELAÇÃO COM A FORMAÇÃO CONTINUADA}

Valente (1997) nos questiona sobre o que seria o uso inteligente do computador em sala de aula. Podemos ampliar essa questão em relação a que seria o uso inteligente da tecnologia em sala de aula, uma vez que a tecnologia pode assumir diferentes papeis. Dependendo do uso que fazemos da tecnologia, o computador pode configurar-se uma máquina de ensino ou uma ferramenta educacional (VALENTE, 1993). O computador como máquina de ensino para Valente (1993) caracteriza-se por meio de tutoriais, exercício-e-prática, jogos e simulação, e destaca-se apenas por computadorizar métodos tradicionais de ensino, sendo usado para mostrar aplicações/representações ou para fixar o conteúdo ensinado anteriormente. Enquanto que o computador como ferramenta educacional, deixa de ser apenas um instrumento e passa a ser a ferramenta com a qual o aluno aprende, sendo usado para ensinar conteúdos.

Nesse sentido, Valente (1999, p. 1) considera que: “A aprendizagem pode ocorrer basicamente de duas maneiras: A informação é memorizada ou é processada pelos esquemas mentais e esse processamento acaba enriquecendo esses esquemas. Neste último caso, o conhecimento é construído". Assim, compreendemos aportados em Valente (1999) que o computador pode ser um facilitador do processo de construção de conhecimento, se for utilizado no processo educacional pautado em métodos que favoreçam esse sentido.

A partir do exposto, entendemos que a forma como o professor utiliza o computador pode estar relacionada à formação que recebe em relação às 
tecnologias na educação. Nesse sentido o trabalho de Bueno (2013) revela que infelizmente a educação ainda segue o modelo de "linha de montagem", sendo necessário aprofundar a formação continuada dos professores, "destacando, sobretudo, o caráter histórico-social da tecnologia" (BUENO, 2013, p. 420). A autora sugere que uma formação nesse sentido, possibilitaria que tanto alunos quanto professores compreendessem como, por que e com que finalidade se desenvolveu a tecnologia, despertando uma visão realmente crítica em relação a seu uso (BUENO, 2013).

A mesma autora, destaca também em seu trabalho que os projetos políticopedagógicos das escolas revelam que as tecnologias assumem caráter instrumental, em que o professor exerce uma prática fragmentada trabalhando sozinho, pois os espaços para discussões coletivas não são incentivados (BUENO, 2013).

Assim, esperamos na presente pesquisa discutir como as tecnologias digitais se fazem presentes nas práticas dos professores que ensinam matemática e como podem se relacionar as formações que receberam em relação às tecnologias na educação e para o ensino de Matemática, especificamente, cuja metodologia deste trabalho é discutida a seguir.

\section{METODOLOGIA}

O presente trabalho é uma pesquisa de cunho qualitativo, em que foram tomados como elemento de coleta de dados, um questionário estruturado no âmbito do Grupo de Estudos e Trabalhos Investigativos em Educação Matemática (GETIEM), a ser respondido por professores da Educação Básica que ensinam Matemática. O questionário foi composto por nove questões abertas e três questões de múltipla escolha com o objetivo de saber se os professores utilizam tecnologias em sala de aula, o que faz com que os professores utilizem ou não tecnologias em 
sala de aula, quais tecnologias utilizam, como as tecnologias se fazem presentes na prática desses professores e sua concepção em relação ao uso das tecnologias no ensino de Matemática. Além de questões que permitissem identificar se tiveram formação em relação ao uso de tecnologias digitais na educação e no ensino da Matemática, o que essas formações abordaram, e o interesse em participarem de grupos ou cursos de tecnologias digitais e o ensino de Matemática e ainda, o que gostariam que fosse abordado nessas formações.

Entramos em contato com o técnico de Matemática de um dos 32 (trinta e dois) Núcleos Regionais de Educação do Estado do Paraná solicitando que enviasse o questionário por e-mail e impresso, aos professores que ensinam matemática em uma das escolas que integra esse Núcleo Regional de Educação para que o respondessem. Além dos professores desse Núcleo Regional de Educação, também responderam ao questionário que Ihes foi enviado por e-mail, alunos de um curso de Mestrado em Ensino. A participação na pesquisa pelos professores foi voluntária, sendo os participantes informados do objetivo por meio de uma carta enviada juntamente com o Termo de consentimento livre e esclarecido, que aqueles que quisessem participar preenchiam e retornavam juntamente com o questionário. Ao todo tivemos o retorno de 14 (quatorze) questionários.

Portanto, tomamos como elementos de análise as respostas de quatorze professores da Educação Básica, sendo seis também estudantes da pós-graduação, todos professores que ensinam Matemática na Educação Básica que responderam ao questionário composto por 11 questões, que pode ser verificado no Quadro 1. 
Quadro 1: Questões. Fonte: Autores

\section{Questões Relacionadas a Tecnologias Digitais}

1. Você utiliza Tecnologias Digitais em suas aulas?

( ) Sempre ( ) Às vezes ( ) Nunca

2. O que te leva a utilizar (ou não) Tecnologias Digitais em suas aulas?

Caso não utilize, vá para a questão 7.

3. Quais Tecnologias Digitais você utiliza em suas aulas?
( ) Televisor ( ) Computador
( ) Tablet ( ) DVD
( ) Calculadora ( ) Equipamento de Som ( ) Internet ( ) Celular
( ) Projetor Multimídia( ) Softwares/aplicativos

Outras:

4. Você utiliza Tecnologias Digitais em suas aulas para ensinar novos conteúdos? Em caso afirmativo descreva uma situação em que você utilizou Tecnologias Digitais com este objetivo.

5. Você utiliza Tecnologias Digitais em suas aulas para mostrar aplicações/representações de elementos matemáticos? Em caso afirmativo descreva uma situação em que você utilizou Tecnologias Digitais com este objetivo.

6. Você utiliza Tecnologias Digitais em suas aulas para fixar o conteúdo ensinado anteriormente? Em caso afirmativo descreva uma situação em que você utilizou Tecnologias Digitais com este objetivo.

7. Você participou de cursos, especializações e/ou capacitações relacionadas às Tecnologias Digitais na Educação? O que foi abordado nesses cursos?

8. Você participou de cursos, especializações e/ou capacitações relacionadas às Tecnologias Digitais no ensino de Matemática? O que foi abordado nesses cursos?

9. Você teria interesse em participar de:

( ) cursos de curta duração envolvendo Tecnologias Digitais e o ensino de Matemática

( ) grupo de estudos envolvendo Tecnologias Digitais e o ensino de Matemática com encontros periódicos (mensais/quinzenais)

10. O que você gostaria que fosse abordado nesses cursos ou grupos de estudo?

11. Caso queira fazer alguma sugestão, utilize o espaço abaixo:

Obrigado pela sua participação!

\section{RESUltAdos E DiscussÃo}

As questões que nos interessam, dado o objetivo deste trabalho, se referem às $2,4,5,6,7$ e 8 . A questão 2 indagou os motivos que levam o professor a utilizar (ou não) tecnologias digitais em sala de aula e teve como principal objetivo compreender os motivos pelos quais os professores utilizam ou não as tecnologias. Com as 
questões 4, 5 e 6, pretendemos identificar como as tecnologias se fazem presentes nas práticas dos professores e também as concepções dos professores quanto as tecnologias. A questão 4 "Você utiliza tecnologias em suas aulas para ensinar novos conteúdos?", a questão 5: "Você utiliza tecnologias em suas aulas para mostrar aplicações/representações de elementos matemáticos?" e a questão 6: "Você utiliza tecnologias em suas aulas para fixar o conteúdo ensinado anteriormente?" objetivam identificar o(s) uso(s) que os professores fazem das tecnologias em sala de aula, e se conseguem diferenciar a forma como utilizam essa tecnologia. Todas essas questões eram seguidas de uma solicitação complementar para que em caso afirmativo descrevessem uma situação em que utilizaram tecnologias digitais em suas práticas em sala de aula com esse objetivo.

E por último as questões 7 e 8 se referiam respectivamente a formação que receberam em relação às tecnologias digitais e em relação a essas no ensino de Matemática, especificamente.

Apresentamos na próxima seção excertos das respostas dos professores a essas questões discutindo como as tecnologias digitais se fazem presentes em suas práticas e como podem se relacionar às formações que esses professores receberam, quanto às tecnologias na educação e no ensino de Matemática especificamente. Os nomes dos professores foram omitidos para garantir a confidencialidade dos dados, sendo identificados pela letra A e um número referente à ordenação atribuída aos questionários durante as análises.

\subsection{TECNOLOGIAS E PRÁTICA DOS PROFESSORES QUE ENSINAM MATEMÁTICA .}

A resposta dos professores a questão 2 do questionário revelou que o principal motivo pelo qual utilizam tecnologias digitais em suas aulas é para motivar os alunos, 
tendo sido citado por sete professores, entre os quais o professor A9, cujo excerto revela que:

Utilizo as tecnologias digitais em sala de aula sempre que possível com o intuito de levar a modernidade para as aulas tirando o peso de uma aula tradicional, bem como para chamar a atenção dos alunos e de certa forma interagir melhor com o contexto tecnológico que eles estão inseridos. Além de facilitar o entendimento e o trabalho em sala de aula. (A9).

A última frase citada na resposta do professor A9 parece aludir à aprendizagem do aluno, pois quando cita "facilitar o entendimento", acreditamos se mencionar a aprendizagem, que, no entanto parece ser secundária, visto que utiliza o termo "além" ao iniciar a frase. Portanto, identificamos nessas respostas que a tecnologia se faz presente na prática dos professores como elemento motivador para o ensino dos conteúdos e também para a aprendizagem que é citada por três professores. Porém, apenas a resposta do professor A8 retrata claramente essa relação com a aprendizagem:

Buscando abordagem diferenciada de assuntos matemáticos, visando uma maior clareza e aprendizagem dos alunos em aulas como ferramenta de apoio alguns meios tecnológicos. (A8).

Entretanto, ao compararmos a resposta desse professor (A8) a questão 4, referente a utilizar tecnologias para ensinar novos conteúdos, observamos que seu relato revela que o uso que faz da tecnologia no ensino da matemática se limita a verificação de cálculos e conclusão do conteúdo, isto é, numa abordagem de revisão ou fixação do que foi "ensinado" sem o uso do computador:

Para o estudo das funções trigonométricas e ângulos, utilizado software para análise gráfica e animação para veracidade dos cálculos realizados durante a aula, como forma de fortalecer e auxiliar no entendimento do assunto, onde num 10 momento trabalhou-se com geoplano circular, em 
seguida realizado cálculos e resolução de exercícios durante a aula, então para fechamento num 2 ㅇ momento foi utilizado o software no laboratório de informática do colégio. (A8.)

Nesse sentido, as respostas desse professor (A8) às questões seguintes do questionário 5 e 6, revelam por sua semelhança em relação ao uso da tecnologia no ensino de Matemática, que há dificuldade do professor (A8) em compreender os diferentes usos da tecnologia no ensino:

Sim, como forma de motivação inicial em alguns casos. Neste caso usado o computador, para mostrar aplicação da matemática em áreas como artes, geografia e astronomia. (Resposta do professor A8 a questão 6).

Como descrito na questão 4, utilizado para fechamento do que já foi trabalhado durante as aulas.(Resposta do professor A8 a questão 7).

Em todas as situações descritas na questão 4 quando os professores responderam positivamente a questão quanto a utilizarem tecnologia para ensinar novos conteúdos, as respostas revelam que há confusão quanto a que compreendem como utilizar a tecnologia para ensinar conteúdos, na perspectiva de Valente (1993) em relação aos diferentes usos do computador na educação. Consideram que se a tecnologia anteceder a explicação do conteúdo já se configura como ferramenta de ensino, como pode ser lido nos excertos:

Já utilizei o ábaco e o material dourado on-line para introduzir o conteúdo de operações básicas da Matemática com alunos do 6ำ ano e sala de apoio à aprendizagem. (A3).

Ao dar a introdução de um novo conteúdo já utilizei vídeos, imagens e a própria calculadora, antes de demonstrar a teoria. Por exemplo, antes de ensinar o plano cartesiano para uma turma de 8 o ano, os alunos jogaram online (jogo gratuito disponível na internet) batalha naval, jogo que se aproxima do conteúdo plano cartesiano por tratar de localização. (A9). 
Outro ponto citado por três professores é tornar o trabalho mais prático:

Pode agilizar o acesso à determinada informação, pesquisas, simulações, entre outros. (A3).

Um professor não respondeu a questão 2 e uma professora relatou que embora goste de utilizar tecnologias não consegue utilizar devido a:

[...] precariedade de tais tecnologias e da internet em minha escola e a falta de conhecimento para utilizar alguns aparelhos. (A1)

Quanto a questão 5 sobre utilizar tecnologias para mostrar aplicações/representações de elementos matemáticos e a questão 6 para fixar conteúdos, três professores referiram que ao responderem a questão 5 sua resposta se aplicava também a questão 6:

Sim. Já apresentei, por exemplo, filmes que relatam a imensidão do universo e a importância de unidades minúsculas de medida quando trabalhamos com o conteúdo notação cientifica. (A9).

Creio que a resposta da questão anterior também se enquadra em fixação do conteúdo. (A9).

Três professores remeteram a utilização de jogos de computador para fixar conteúdos, o que se alinha ao exposto por Valente (1993) quanto à utilização de jogos nesse sentido:

Sim, uso com frequência jogos digitais para a fixação de conteúdos. (A10).

Quanto à formação dos professores relacionada ao uso das tecnologias digitais, suas respostas revelam que quatro professores nunca realizaram nenhum curso relacionado às tecnologias digitais na educação ou no ensino de matemática, e metade dos professores que responderam ao questionário nunca participaram de formações específicas no ensino de Matemática, como pode-se verificar na resposta do professor A8: 
Nunca participei, sempre gostei de tecnologia e busquei por conta própria me integrar de formas distintas de trabalhar com o ensino de matemática, também já dei cursos sobre essas formas e como utilizar, como decidir se é viável ou não naquele momento, e as possibilidades de se criar estratégias de ensino utilizando tecnologia. (A8).

Ao observarmos as formações que receberam relacionadas às tecnologias digitais na educação predomina o caráter instrumentalista:

Os procedimentos de como usar e produzir apresentação para a aula. (A14).

Já participei de curso para aprender a utilizar o tablete e a lousa digital. (A2).

O mesmo foi verificado em relação às formações que participaram relacionadas ao ensino da matemática, em que foram citados predominantemente cursos para ensinar a usar softwares sem mencionarem explanações ou discussões pedagógicas realizadas durante as formações quanto ao potencial para o uso no ensino em sala de aula.

Sim. Participei de um curso para trabalhar com a Lousa Digital e também com o Software Maple. Os professores que ministraram os cursos, primeiramente apresentaram os principais elementos que faziam parte do programa. Na sequência passaram os instaladores para cada um dos alunos instalarem em suas máquinas. Os professores apresentavam os exemplos e os alunos registravam os comandos em seus computadores. (A5).

Assim, o caráter instrumental prevalece nas formações relacionadas às tecnologias tanto na educação quanto no ensino da Matemática especificamente.

Sintetizamos os resultados no Quadro 2: 
Quadro 2: Resultados. Fonte : autores

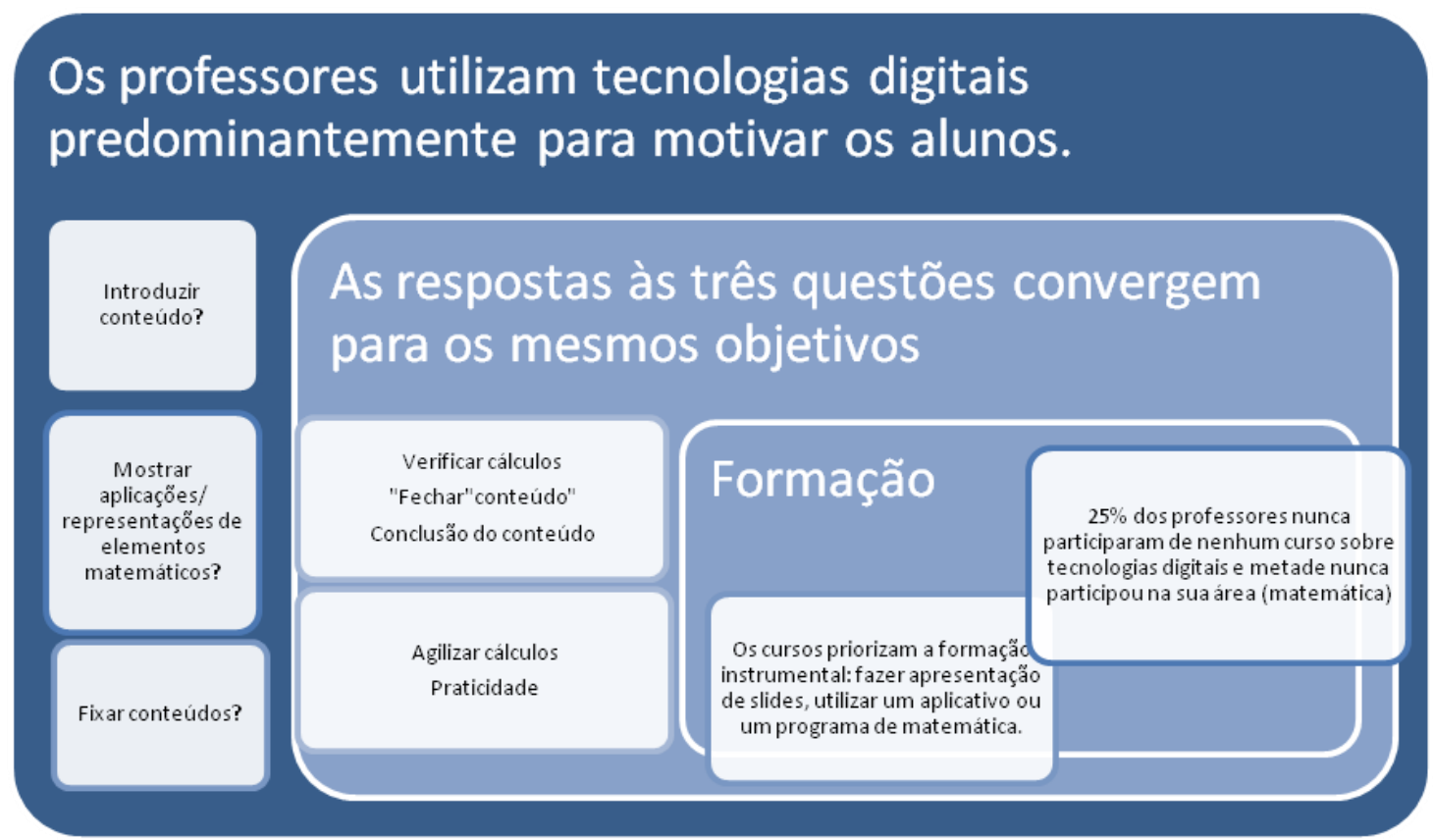

Identificamos dessa forma (Quadro 2) que o que leva os professores a utilizarem tecnologias digitais em suas aulas está relacionado a motivarem seus alunos, não diferenciando o seu uso para introduzir, mostrar aplicações e representações de elementos matemáticos ou fixar conteúdos, pois, o uso que fazem, se refere ao uso da tecnologia para agilizar ou conferir cálculos, utilizar um vídeo para ilustrar o conteúdo, ou seja, como citado anteriormente, após explicarem o conteúdo. O que mostra que para eles, o aluno aprende por meio da explicação do professor, e a tecnologia apenas complementa essa explicação. Essa forma de compreender o uso das tecnologias digitais é coerente com as formações, que, quando participaram, privilegiam o caráter instrumental, ou seja, como manusear determinado programa, sem uma discussão pedagógica das mudanças que as tecnologias digitais podem favorecer à prática pedagógica. 


\section{CONCLUSÃO}

As respostas dos professores ao questionário revelam que as tecnologias quando utilizadas em sala de aula pelos professores apresentam as características do ensino tradicional computadorizado, e, não são, portanto, utilizadas como ferramentas educacionais (VALENTE, 1993), pois, as respostas dos professores às questões 4, 5 e 6 denotam que os docentes não conseguem distinguir o computador como "máquina de ensinar" do computador como "ferramenta de ensino" (VALENTE, 1993); dado que as respostas a questão 4 não apresentam elementos que mostrem a utilização do computador para ensinar, sendo citadas apenas situações em que o computador é utilizado para introduzir ou fixar conteúdos.

Portanto, isso revela que precisamos repensar a formação de professores em relação às tecnologias na educação privilegiando o caráter pedagógico ao instrumental, uma vez que identificamos que a forma como os professores utilizam as tecnologias em sala de aula, reproduz as formações que recebem, as quais privilegiam a verificação de resultados, simulações e resolução de exercícios. O que leva a adaptação do uso do computador, softwares e internet às antigas metodologias utilizadas em sala de aula, diminuindo as possibilidades de um ensino inovador permeado pelo uso das tecnologias digitais.

\section{AGRADECIMENTOS}

O presente estudo integra o projeto de pesquisa "Análise de tarefas como prática para (res)significação de conhecimentos profissionais de professores de matemática", financiado pela Fundação Araucária, dos estudos realizados pelo Grupo de Estudos Teóricos e Investigativos em Educação Matemática (GETIEM) da linha Tecnologias na Educação e também a pesquisa de pós-doutorado junto ao 
Programa de Pós Graduação em Ensino de Ciências e Tecnologia da Universidade Tecnológica Federal do Paraná.

\section{REFERÊNCIAS}

BUENO, N. de L. Tecnologia educacional e reificação: uma abordagem crítica a partir de Marxs e Luckás. 2013. 503f. Tese (Doutorado em Educação). Programa de Pós Graduação em Educação. Universidade Federal do Paraná, Curitiba, 2013.

VALENTE, J. A. O uso inteligente do computado na educação. Pátio - revista pedagógica. Editora Artes Médicas Sul. 1997, ano 1, no 1, p.19-21.

VALENTE, J. A. Diferentes usos do computado na educação. Em Aberto, Brasília, 1993, ano 12, n.57.

VALENTE, J. A. Análise dos diferentes tipos de software usados na educação IN Valente, J. A. O computador na sociedade do conhecimento. Campinas: UNICAMP/ NIED, 1999. 156p.

Recebido em: Julho de 2017. Publicado em: Agosto de 2017. 